\title{
Concentration Dependent Effect of Heavy Metals on Soil Carbon Mineralization
}

\author{
Buddhi Charana Walpola and Min-Ho Yoon* \\ Department of Bio-Environmental Chemistry, College of Agriculture and Life Sciences, \\ Chungnam National University, Daejeon, 305-764, Korea.
}

\begin{abstract}
The present laboratory investigation was conducted to assess the effect of heavy metals on carbon mineralization. Soil was treated with three concentrations $\left(50,100\right.$ and $150 \mu \mathrm{mol} \mathrm{g}^{-1}$ soil) of two heavy metals ( $\mathrm{Cd}$ and $\mathrm{Zn}$ ) in a factorial combination of treatments replicated four times. Determination of carbon mineralization was carried out at 3, 7, 14, 21, 28, 42 and 56 days after metal treatments.. The amount of $\mathrm{CO}_{2}-\mathrm{C}$ released from heavy metal treated soils was found to be decreased at an increasing rate during the first 28 days, followed by slow release as incubation progressed. The total amounts of $\mathrm{CO}_{2}-\mathrm{C}$ released were 448,382 and $348 \mathrm{mg} \mathrm{kg}^{-1}$ soil respectively for soils treated with 50,100 and $150 \mu \mathrm{mol} \mathrm{g}^{-1}$ soil of $\mathrm{Zn}$. The corresponding figures for Cd treated soils were 406,354 and $282 \mathrm{mg} \mathrm{kg}^{-1}$ soil implying that dose-dependent reduction in cumulative $\mathrm{CO}_{2}-\mathrm{C}$ released from soils. The inhibition of carbon mineralization was found to be high in $\mathrm{Cd}$ treated soils than that of $\mathrm{Zn}$ treated. Therefore, tolerance and adaptation of the microbial community is likely to be related to the concentration and the type of metal. According to the results, carbon mineralization can be considered as possible indicator of soil pollution by means of heavy metals.
\end{abstract}

Key words: Heavy metals, Incubation, Carbon mineralization, Soil pollution

\section{Introduction}

Heavy metals are natural components of the environment, but are of concern as they are being added to soil, water and air in increasing amounts. They enter the soil through various sources, including wastes from mines and smelters, atmospheric deposition, animal manures and sewage sludge and in some circumstances as inorganic fertilizers (Gazso, 2001). In recent decades, there has been increasing interest in heavy metals, not only because of toxicity to animals, plant and other living organisms, but also they can not be removed easily from the soils, as they become irreversibly immobilized within different soil components (humified organic matter, $\mathrm{Fe}$ and $\mathrm{Al}$ oxides and hydroxides, clay particles etc.). As heavy metals can persist in the soil for tens of thousands of years, the long-term effect of these elements on soil productivity is a matter of intensively discussed. Due to the repeated and uncontrolled additions to soil, microorganisms responsible for nitrogen fixation, assimilation and degradation of organic residues to release nutrients could also be affected interfering key bio-

\footnotetext{
Received : 2012. 6. 25 Accepted : 2012. 7. 25

*Corresponding author : Phone: +82428216733

E-mail: mhyoon@cnu.ac.kr
}

chemical processes and ecological balance (Brookes, 1995).

Heavy metals are known to exert toxic effects on microbial processes in soils and different aspects of their toxicity towards microorganisms and microbial meditated processes in soil. The soil microbial population is under tremendous pressure due to contamination of soil by a variety of toxic heavy metals. Toxic effects on microorganisms manifest in numerous ways such as decrease in litter decomposition and nitrogen fixation, less efficient nutrient cycling, impaired enzyme synthesis and activity in soil, sediments and water. Soil microbial functions such as respiration, carbon and nitrogen mineralization, biological nitrogen fixation etc., can thus be used for monitoring heavy metal pollution in soil (Ultra et al., 2005).

The concentration of a toxic metal that affects the growth and survival of different microorganisms varied greatly. Zinc (Zn) and Cadmium (Cd) are two heavy metals naturally occurring in small amounts in soils. $\mathrm{Cd}$ is a potentially toxic metal with no known biological function. $\mathrm{Zn}$ as a micronutrient is an essential element to maintain metabolic functions of living organisms. However, both essential and nonessential elements occurring in too high concentrations in soils can harm organisms and therefore are a potential risk to terrestrial environments 
(Kao et al., 2006).

Microbial respiration is an effective measure of the rate of carbon mineralization since, about $70 \%$ of carbon added to soil is lost as $\mathrm{CO}_{2}$, mainly as a product of microbial respiration. Heavy metals present in soil can significantly reduce the rate of decomposition because microbial activity is adversely affected by heavy metal toxicity (Burkhardt et al., 1993). Therefore, the amount of $\mathrm{CO}_{2}$ evolved is a very reliable indicator of the effect of metal contamination on microbial activity. This is because respiration has been found to suffer the greatest reduction when compared with the other microbial parameters like biomass may be reduced only slightly. Under this background, the present study was undertaken to assess the effect of heavy metal concentration on carbon mineralization as measured by microbial respiration.

\section{Materials and Methods}

Experimental area and soil The experiment was conducted at the Faculty of Agriculture, University of Ruhuna, Sri Lanka. According to the agro-ecological classification (Panabokke, 1980), the region of investigation comes under agro-ecological region $\mathrm{WL}_{2}$ (low country wet zone). The soil used in this study belongs to Red Yellow Podzolic great soil group and is classified as Hapludults according to the USDA soil taxonomy (Mapa et al., 1999). The climate of the area is tropical monsoonal (Panabokke, 1980), with a warm wet period (April to June) and a relatively dry period (January to March). The area receives an annual rainfall of around 2,500 $\mathrm{mm}$. The distribution of rain is bi-model. Annual mean air temperature of the area is $22-30^{\circ} \mathrm{C}$ and the relative humidity is about $80 \%$.

Soil sampling Soil samples were collected randomly from several selected locations at the research farm of Faculty of Agriculture, University of Ruhuna, Sri Lanka. After removing the surface litter, soil samples were taken from $0-15 \mathrm{~cm}$ depth by using an auger. They were then mixed thoroughly in order to make a composite sample. Physico-chemical characteristics of the soil were determined using standard methods (Table 1).

Treatments Sub samples of $50 \mathrm{~g}$ of homogeneously mixed air dried soil were placed in glass bottles. Bottles were watered to adjust the moisture content to $50 \%$ of the
Table 1. Physico-chemical characteristics of the soil. Values given here are the means of three replicates $(n=3)$.

\begin{tabular}{lc}
\hline \hline Properties & Value \\
\hline Sand \% & 60.4 \\
Silt \% & 30.8 \\
Clay \% & 7.6 \\
Soil pH & 5.15 \\
Soil moisture content \% & 5.7 \\
Soil C \% & 1.008 \\
Soil N \% & 0.126 \\
Soil EC (mS cm $\left.{ }^{-1}\right)$ & 0.15 \\
Soil CEC (cmol Kg $\left.{ }^{-1}\right)$ & 9.05 \\
Soil bulk density $\left(\mathrm{g} \mathrm{cm}^{-3}\right)$ & 1.74 \\
\hline
\end{tabular}

field capacity (dry basis) and maintained by daily monitoring and adding water when necessary. Bottles were then kept in dark for two weeks prior to addition of treatments. After two-week pre-incubation period, the glass bottles were opened and $50 \mu \mathrm{mol}, 100 \mu \mathrm{mol}, 150$ $\mu \mathrm{mol}$ of $\mathrm{CdCl}_{2}$ and $\mathrm{ZnCl}_{2}$, were added separately and mixed thoroughly with the soil. Soil samples without being treated with heavy metals were used as control. The treated soil samples along with the controls were incubated in the dark at room temperature $\left(25 \pm 1^{\circ} \mathrm{C}\right)$. Constant moisture content of the soil was maintained throughout the incubation period.

Carbon mineralization Soil samples were placed in gas-tight glass containers along with a vial containing 10 $\mathrm{ml}$ of $2 \mathrm{M} \mathrm{NaOH}$ to trap $\mathrm{CO}_{2}$ and a vial of water to maintain humidity. Soil was incubated at room temperature $(25+$ $1^{\circ} \mathrm{C}$ ) in the dark and $\mathrm{NaOH}$ traps were replaced at 3, 7, 14, 21, 28, 42 and 56 days after the treatment. Un-reacted alkali in the $\mathrm{NaOH}$ traps was titrated with $1 \mathrm{M} \mathrm{HCl}$ to determine $\mathrm{CO}_{2}-\mathrm{C}$ released from the soil (Anderson, 1982).

Statistical Analysis Data generated were subjected to analysis of variance (ANOVA) for a Completely Randomized Design (CRD) with four replicates using SAS software (SAS Institute, 1988). Least significant difference at $\mathrm{P} \leq 0.05$ was used to separate the means.

\section{Results and Discussion}

Periodic changes in the amount of $\mathrm{CO}_{2}-\mathrm{C}$ released from the heavy metal treated soils are depicted in Fig. 1. The amount of $\mathrm{CO}_{2}-\mathrm{C}$ released from the heavy metal treated 


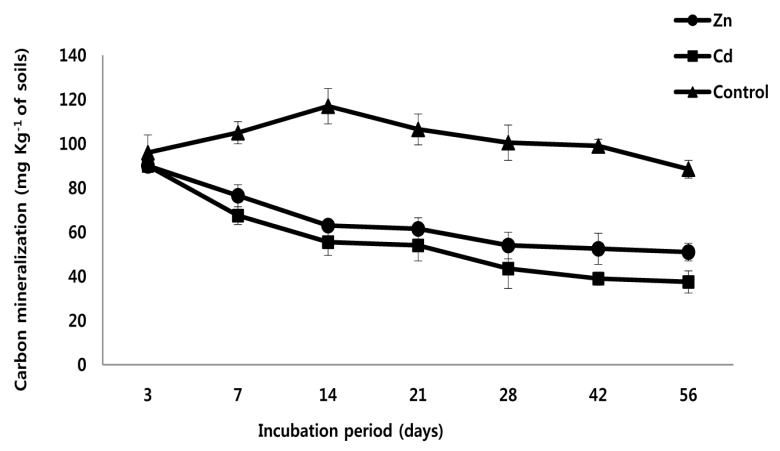

(a)

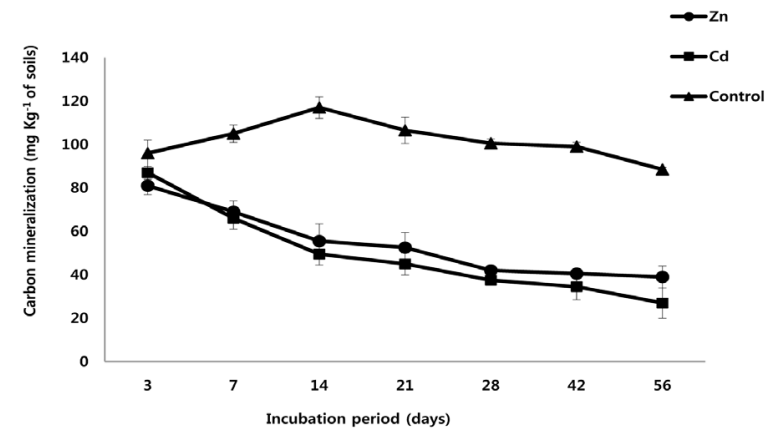

(b)

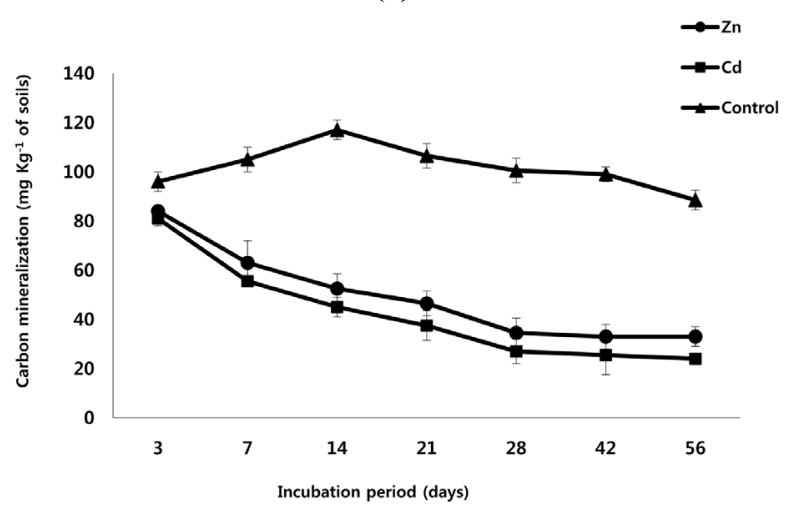

(c)

Fig. 1. Carbon mineralization of the soil treated with heavy metal $\mathrm{Cd}$ and $\mathrm{Zn}$ in different concentrations. Values given here are the means $(n=4) \pm$ standard deviation.(a) 50 $\mu \mathrm{mol} \mathrm{g}{ }^{-1}$ soil (b) $100 \mu \mathrm{mol} \mathrm{g}{ }^{-1}$ soil (c) $150 \mu \mathrm{mol} \mathrm{g}{ }^{-1}$ soil.

soils was found to be decreased at an increasing rate during the first 28 days and followed by decreased at decreasing rates when incubation was progressed. A possible reason for the initial decrease in increasing rate of carbon mineralization may be due to the toxicity of the heavy metal. It is further indicated from the results that a considerable period of time is needed for the adaptation of microorganisms. Min Lio (2005), who studied soil microbial parameters of a soil polluted with heavy metals also reported an increased $\mathrm{ED}_{50}$ (Ecological dosage) over time for different heavy metals. Therefore, carbon mineralization can be used as possible indicators of soil environmental quality in toxicity assays as suggested by
Yao et al. (2000). Furthermore, different heavy metals with different concentrations resulted in different rates of $\mathrm{CO}_{2}$ evolution. The amount of $\mathrm{CO}_{2}$ evolved from heavy metals treated soil was lower than that of the control throughout the incubation period.

The heavy metal $\mathrm{Zn}$ with concentration of $50 \mu \mathrm{mol} \mathrm{g}^{-1}$ treated soils showed the relatively high carbon mineralization than the other treatments and heavy metal $\mathrm{Cd}$ with concentration of $150 \mu \mathrm{mol} \mathrm{g}^{-1}$ treated soils showed the lowest carbon mineralization throughout the incubation. (Fig. 2). This is not surprising; microorganisms differ in their sensitivity to metal toxicity and sufficient metal exposure will result in immediate death of cells due to disruption of essential functions, and to more gradual changes in population sizes due to changes in viability or competitive ability (Nwachukwu and Pulford, 2011). It is possible that at lower concentrations or short-term exposure to the heavy metals, the microorganisms may compensate by a higher carbon turnover and so lead to a gradual change in viability. At elevated concentrations however, heavy metals cause immediate death of microorganisms.

At the beginning of incubation the carbon mineralization of heavy metal $\mathrm{Zn}$ applied soils were 90, 81 and 84 $\mathrm{mg} \mathrm{kg}^{-1}$ soil respectively for the treatments of 50, 100 and $150 \mu \mathrm{mol} \mathrm{g}^{-1}$ of soil. Then after completion of the incubation period (after 56 days) the values has been changed to 51,39 and $33 \mathrm{mg} \mathrm{kg}^{-1}$ soil for above respective treatments. The respective values for the $\mathrm{Cd}$ applied soils were 90,81 and $81 \mathrm{mg} \mathrm{kg}^{-1}$ soil for the treatments of 50,100 and $150 \mu \mathrm{mol} \mathrm{g}^{-1}$ at the beginning of the incubation and $37.5,27$ and $24 \mathrm{mg} \mathrm{kg}^{-1}$ soil for respective treatments at the end of the incubation. The heavy metal addition caused reductions in the rates of $\mathrm{CO}_{2}$ evolution by 43,52 , $61,58,67$ and $70 \%$ respectively for the treatments of 50 , 100 and $150 \mu \mathrm{mol} \mathrm{g}^{-1}$ of soil of $\mathrm{Zn}$ and $\mathrm{Cd}$. This shows that $\mathrm{Cd}$ has higher inhibitory effect on carbon mineralization than $\mathrm{Zn}$. Corresponding to this result, it has been reported that $\mathrm{Cd}$ has higher inhibitory effect on nitrogen mineralization from our earlier research (Walpola et al., 2011).

Though substantial reduction in microbial activity has been reported as the short-term response to toxic metals, habitats that have had high levels of metal contamination for years may still have microbial populations and activities that are smaller than the microbial populations and activities in uncontaminated habitats (Utgikar et al., 2004). The Nwuche and Ugoji (2008) reported that the rate of respiration of the soil microbial populations was 


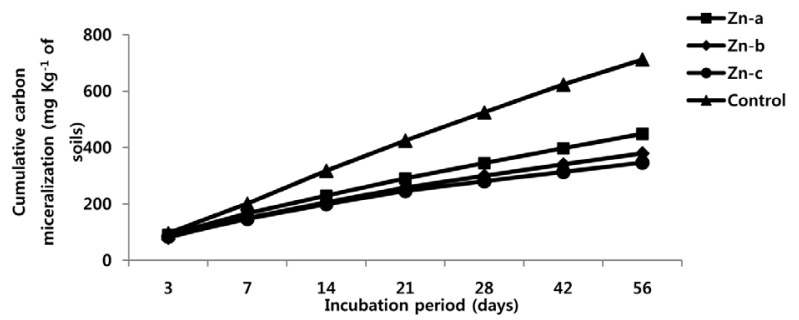

(a)

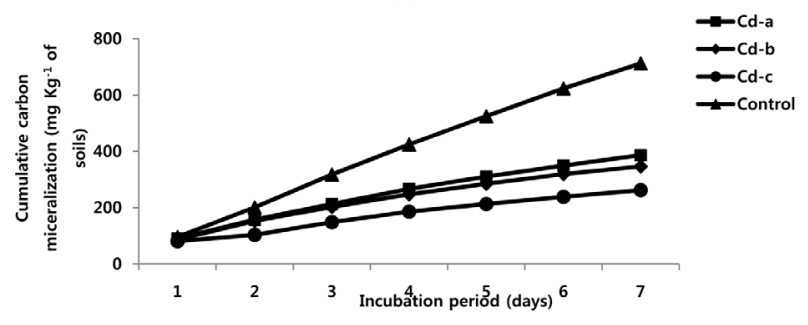

(b)

Fig 2. Cumulative carbon mineralization of the soil treated with different $\mathrm{Cd}$ and $\mathrm{Zn}$ in different concentrations. (a) $\mathbf{5 0}$ $\mu \mathrm{mol} \mathrm{g}{ }^{-1}$ soil (b) $100 \mu \mathrm{mol} \mathrm{g}^{-1}$ soil (c) $150 \mu \mathrm{mol} \mathrm{g}{ }^{-1}$ soil.

inhibited by the metals and it was $2.51-2.56 \mu \mathrm{g}$ of $\mathrm{C} \mathrm{g}^{-1}$ at the beginning declined to $0.98,1.08$ and $1.61 \mu \mathrm{g}$ of $\mathrm{C} \mathrm{g}^{-1}$ in the $\mathrm{Cu}: \mathrm{Zn}, \mathrm{Cu}$ and $\mathrm{Zn}$ treated soils by the end of the incubation.

There was a significant difference ( $\mathrm{P} \leq 0.05)$ among the control and heavy metal treated soils throughout the incubation period. However, there was no significant (P $\leq 0.05)$ variation was observed among the treatments until day 3 of the incubation. The amount of $\mathrm{CO}_{2}-\mathrm{C}$ released from $\mathrm{Zn}$ and $\mathrm{Cd}$ treated soils were significantly $(\mathrm{P}$ $\leq 0.05$ ) difference from the control since day 7 onwards until end of the incubation. The heavy metal $\mathrm{Zn}$ with concentration of $50 \mu \mathrm{mol} \mathrm{g} \mathrm{g}^{-1}$ treated soils and $\mathrm{Cd}$ with concentration of $150 \mu \mathrm{mol} \mathrm{g} \mathrm{g}^{-1}$ treated soils showed the highest and the least significant difference $(\mathrm{P} \leq 0.05)$ respectively from the control throughout the incubation.

The cumulative carbon mineralization of the soil were 448, 382 and $348 \mathrm{mg} \mathrm{kg}^{-1}$ soil respectively for soils received 50, 100 and $150 \mu \mathrm{mol} \mathrm{g}^{-1}$ soil of $\mathrm{Zn}$. The corresponding figures for $\mathrm{Cd}$ treated soils were 406,354 and $282 \mathrm{mg} \mathrm{kg}^{-1}$ soil implying that dose-dependent reduction in cumulative $\mathrm{CO}_{2}-\mathrm{C}$ released from soils.

\section{Conclusions}

The inhibition of carbon mineralization was found to be high in $\mathrm{Cd}$ treated soils than that of $\mathrm{Zn}$ treated. Therefore, tolerance and adaptation of the microbial community is likely to be related to the concentration and the type of metal. According to the results, carbon mineralization can be considered as possible indicators of soil pollution by means of heavy metals.

\section{References}

Anderson, J.P.E. 1982. Soil respiration. In: page A. L., R. H. Miller and D. R. Keeney (eds) Methods of soil analysis. Part $2,2^{\text {nd }}$ edn. (Agronomy monograph no. 09) American Society of Agronomy and Soil Science Society of America, Madison, Wis. Pp 837-871.

Brookes, P. C. 1995. The use of microbial parameters in monitoring soil pollution by heavy metals. Biol. Fertil. Soils. 19:269-279.

Burkhardt C., H. Insam, T. C. Hutchinson, and H. H. Reber. 1993. Impact of heavy metals on the degradative capabilities of soil bacterial communities. Biol. Fertil. Soils. 16:154-156.

Gazso, L.G. 2001. The key microbial processes in the removal of toxic metals and radionuclides from the environment. (a review) Cent. Eur. J of Ocuup. Environ. Med. 7:178-185.

Kao, P.H., C.C. Huang, and Z.Y. Hseu. 2006. Response of microbial activities to heavy metals in a neutral loamy soil treated with bio solid. Chemosphere. 64:63-70.

Mapa, R.B., S. Somssiri, and S. Nagarajah. 1999. Soils of the wet zone of Sri Lanka. Soil Sci. Soc. SL. Sri Lanka. 1:23-92.

Min Lio, L. Yun-kuo, Z. Xiao-min, and H. Chang-yong. 2005. Toxicity of cadmium to soil microbial biomass and its activity: Effect of incubation time on Cd ecological dose in a paddy soil. J. Zhejiang Univ. Sci. B. 6:324-330.

Nwachukwu, O.I. and I.D. Pulford. 2011. Microbial respiration as an indication of metal toxicity in contaminated organic materials and soil. J. Hazard. Mater. 185:1140-1147.

Nwuche, C.O. and E.O. Ugoji. 2008. Effects of heavy metal pollution on the soil microbial activity. Int. J. Environ. Sci. Tech. 5:409-414.

Panabokke, C.R. 1980. Handbook of the soils of Sri Lanka. J. Soil Sci. Soc. 2:83-85.

SAS Institute. 1988. SAS/STAT user's guide, Release 6.03. SAS Institute, Cary, North Carolina, USA.

Ultra, Jr V. U., A. Yano, K. Iwasaki, S. Tanaka, Kang-YuMei, and K. Sakurai. 2005. Influence of chelating agent addition on copper distribution and microbial activity in soil and copper uptake by brown mustard (Brassica juncea). Soil Sci. Plant Nutr. 51:193-202.

Utgikar, V.P., N. Chaudhary, A. Koeniger, H.H. Tabak, J.R. Haines, and R. Govind. 2004. Toxicity of metals and metal mixtures: Analysis of concentration and time dependence for zinc and copper. Water res. 38:3651-3658.

Walpola, B.C., K.K. I.U. Arunakumara, and M.H. Yoon. 2011. Evaluation of nitrogen mineralization in soil polluted by zinc and cadmium. Korean J. Soil Sci. Fert. 44:559-564.

Yao, H.Y., Z.L. He, M.J. Wilson, and C.D. Campbell. 2000. Microbial biomass and community structure in a sequence of soils with increasing fertility and changing land use. Microb. Ecol. 40:223-237. 